
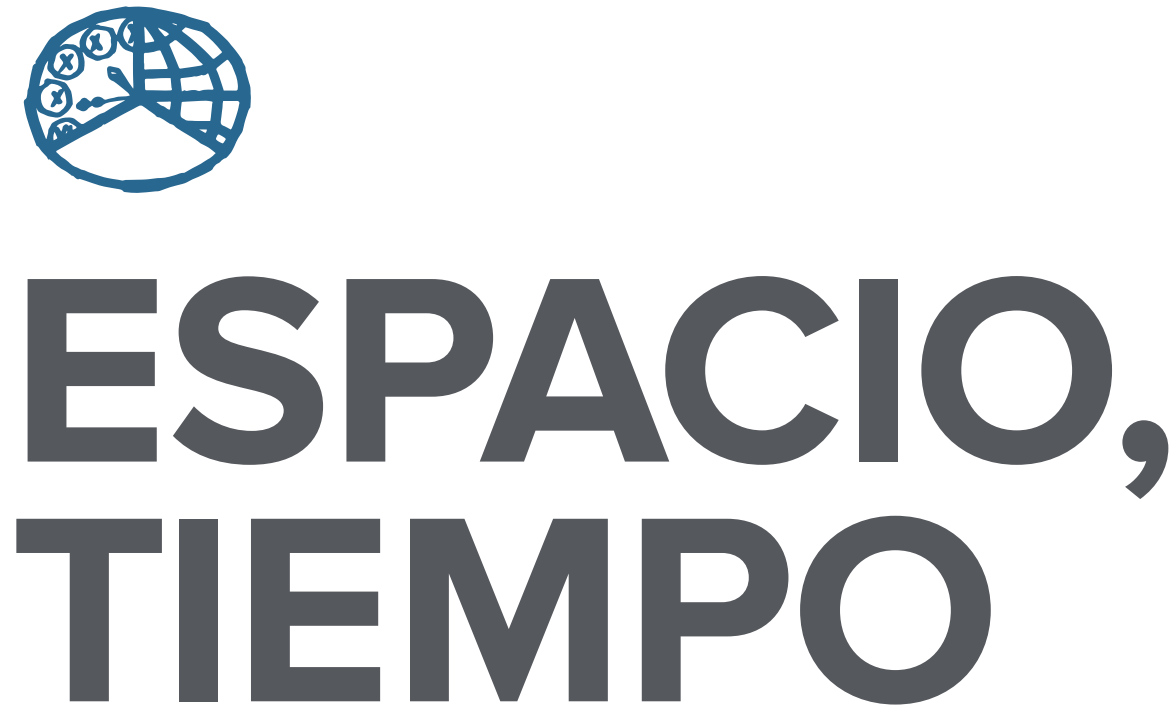

AÑO 2013

NUEVA ÉPOCA

ISSN 1130-4715

E-ISSN 2340-1478
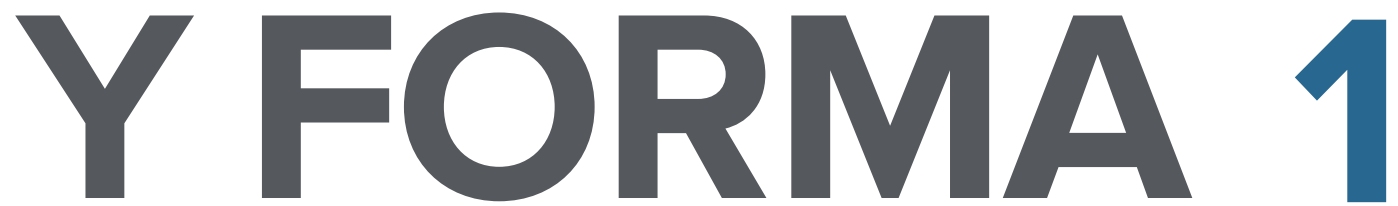

SERIE VII HISTORIA DEL ARTE

REVISTA DE LA FACULTAD DE GEOGRAFÍA E HISTORIA 

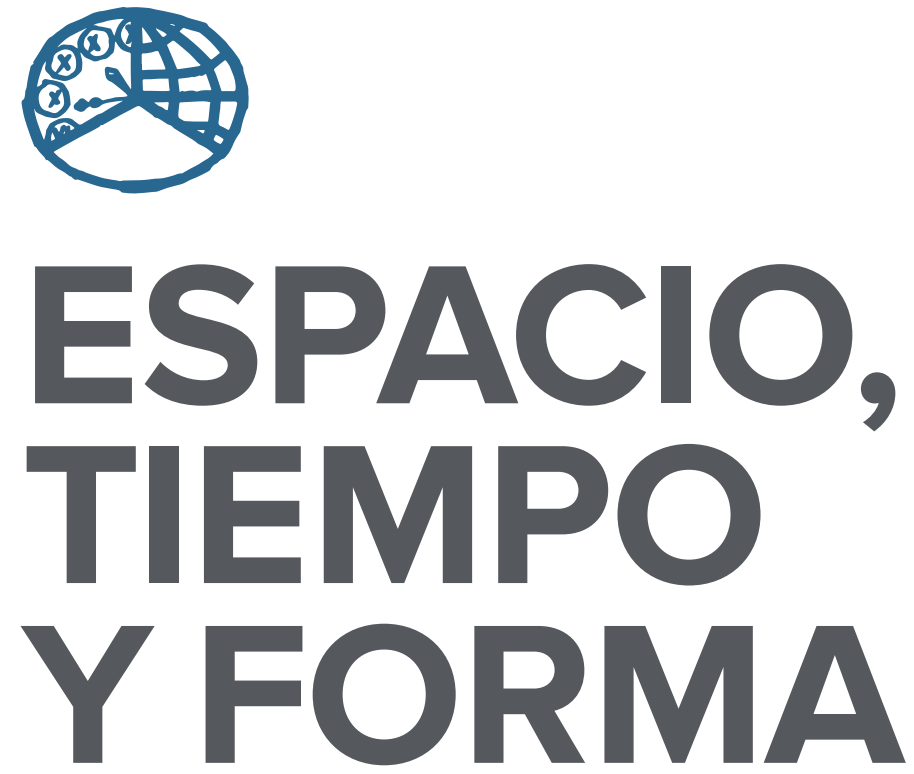

AÑO 2013

NUEVA ÉPOCA

ISSN $1130-4715$

E-ISSN 2340-1478

SERIE VII HISTORIA DEL ARTE

REVISTA DE LA FACULTAD DE GEOGRAFÍA E HISTORIA

http://dx.doi.org/10.5944/etfvii.1.2013

\section{UกED}

UNIVERSIDAD NACIONAL DE EDUCACIÓN A DISTANCIA 
La revista Espacio, Tiempo y Forma (siglas recomendadas: ETF), de la Facultad de Geografía e Historia de la UNED, que inició su publicación el año 1988, está organizada de la siguiente forma:

$$
\begin{aligned}
& \text { SERIE I - Prehistoria y Arqueología } \\
& \text { SERIE II - Historia Antigua } \\
& \text { SERIE III - Historia Medieval } \\
& \text { SERIE IV - Historia Moderna } \\
& \text { SERIE V - Historia Contemporánea } \\
& \text { SERIE VI - Geografía } \\
& \text { SERIE VII - Historia del Arte }
\end{aligned}
$$

Excepcionalmente, algunos volúmenes del año 1988 atienden a la siguiente numeración:

$$
\begin{aligned}
& \mathrm{N}^{\circ} 1 \text { - Historia Contemporánea } \\
& \mathrm{N}^{\circ} 2 \text { - Historia del Arte } \\
& \mathrm{N}^{\circ} 3 \text { - Geografía } \\
& \mathrm{N} .^{\circ} 4 \text { - Historia Moderna }
\end{aligned}
$$

ETF no se solidariza necesariamente con las opiniones expresadas por los autores.

Espacio, Tiempo y Forma, Serie vII está registrada e indexada, entre otros, por los siguientes Repertorios Bibliográficos y Bases de Datos: DICE, ISOC (CINDOC), RESH, IN-RECH, Dialnet, e-spacio, UNED, CIRC, MIAR, FRANCIS, PIO, Ulrich's, SUDOC, 2DB, ERIH (ESF).

\author{
UNIVERSIDAD NACIONAL DE EDUCACIÓN A DISTANCIA \\ Madrid, 2013 \\ SERIE VII · HISTORIA DEL ARTE (NUEVA ÉPOCA) N. ${ }^{\circ} 1,2013$ \\ ISSN $1130-4715 \cdot$ E-ISSN 2340-1478 \\ DEPÓSITO LEGAL \\ $M-21.037-1988$ \\ URL \\ ETF VII · HISTORIA DEL ARTE · http://revistas.uned.es/index.php/ETFVII \\ DISEÑO Y COMPOSICIÓN \\ Ángela Gómez Perea · http://angelagomezperea.com \\ Sandra Romano Martín · http://sandraromano.es \\ Impreso en España · Printed in Spain
}

(c) (1) (8) Esta obra está bajo una licencia Creative Commons

Reconocimiento-NoComercial 4.0 Internacional. 


\title{
RESTAURACIÓN Y METAMORFOSIS DE LOS VALORES DEL PATRIMONIO CULTURAL
}

\section{RESTORATION AND METAMORPHOSIS OF THE VALUES OF CULTURAL HERITAGE}

\author{
Antonio J. Sánchez Fernández ${ }^{1}$ \\ Recibido: 31/03/2013 - Aprobado: 30/09/2013 \\ http://dx.doi.org/10.5944/etfvii.1.2013.5552
}

\section{Resumen}

Este trabajo tiene como objetivo estudiar los valores del patrimonio cultural como un aspecto clave en la actividad de la Restauración. La apreciación de estos valores es compleja porque intervienen factores como la diversidad (hay muchos tipos de factores -culturales, económicos, políticos, estéticos...-) o los cambios con el tiempo. De esta manera, los valores determinan las decisiones que se toman. Sin embargo, asistimos a una transformación del sistema cultural en materia de protección del patrimonio. En primer lugar, clasificamos los significados y valores de los bienes culturales. Además, identificamos los principales mecanismos de transformación y la influencia de los medios de comunicación de masas en la percepción del patrimonio cultural. Finalmente, proponemos unas pautas de revalorización de los objetos culturales. Por otra parte, usamos la disciplina de la semiótica como herramienta transversal para la evaluación de los valores culturales. Así, afirmamos que los bienes culturales y los objetos restaurados se comportan como una estructura comunicativa.

\section{Palabras clave}

Conservación-Restauración; criterios de intervención; Patrimonio histórico-artístico; valores del patrimonio; convencionalización

\section{Abstract}

This work aims to study the values of cultural heritage as a key aspect in the activity of the Restoration. The appreciation of these values is complex because it involves factors such as diversity (there are many types of factors - cultural, economic, politic, aesthetic...-) or changes over time. Therefore, such values determine the decisions made. However, we are witnesses to the transformation of the cultural

1. Doctorando en Conservación-Restauración, Universidad de Sevilla (asrestauracion@hotmail.com). 
system in matters of protection of heritage. First, the meanings and values of the cultural property are classified, and the main mechanisms of the transformation are identified, along with the role played by the Mass Media in influencing perceptions of cultural heritage. Finally, some revaluation guidelines of cultural objects are proposed. Furthermore, the discipline of semiotics is used as a transversal tool for the evaluation of cultural values. Thus, it is affirmed here that cultural property and restored objects behave as a communicative structure.

Keywords

Conservation-Restoration; intervention criteria; historic-artistic Heritage; Heritage values; conventionalization 


\section{INTRODUCCIÓN}

La importancia del patrimonio cultural para el conjunto de la sociedad es indiscutible y poliédrica. Desde la premisa de la doble polaridad de la obra de arte, histórica y estética, y su reflejo en la materialidad, planteamos la necesidad de reflexionar sobre las relaciones entre los valores de los bienes culturales, las intervenciones de conservación-restauración y la percepción de los objetos de Restauración.

Argumentamos la comprensión de los objetos patrimoniales a través de los mecanismos de simbolización como coadyuvante de la disciplina de la conservación-restauración, entendida como momento metodológico de interpretación del patrimonio cultural.

De esta manera, se observa una distorsión conceptual que descansa en la metamorfosis de valores propios de la contemporaneidad y que influye en el cambio, uso y/o manipulación de significados de los objetos histórico-artísticos.

\section{VALORES DE SIMBOLICIDAD DE LOS OBJETOS DE RESTAURACIÓN. MECANISMOS Y TRANSFORMACIONES}

Todos los objetos patrimoniales tienen un significado. Son emblemas que contienen unos valores depositados por ciertas personas. Estos valores conciernen aspectos espirituales como sentimientos, creencias, ideologías... abstracciones, que a su vez, hacen difícil su conceptualización o verbalización.

Así, la naturaleza simbólica de los objetos histórico-artísticos se reconoce en diversos textos oficiales en materia de Restauración.

Ya en la Carta de Atenas se introduce esta concepción simbólica de los monumentos y obras de arte en relación con la educación, como garante de la conservación del patrimonio, induciendo «al entendimiento del significado [de los testimonios de todas las civilizaciones] ${\aleph^{2}}^{2}$ la infancia y la juventud.

En la Carta de Venecia, se define la noción de monumento en torno a varios conceptos como el testimonio constitutivo de «una evolución significativa» o la adquisición, con el tiempo, de «un significado cultural». Ambos preceptos están indicando el requerimiento de una expresión especial, de una manifestación particular o enriquecida por el paso del tiempo, que avance en el estatus de reconocimiento de los objetos histórico-artísticos. Igualmente, en sus primeras líneas, la Carta otorga a las obras monumentales de los pueblos la capacidad de portar «un mensaje espiritual del pasado», en una clara afirmación del carácter comunicativo de los objetos de Restauración, aceptando de forma indirecta, la existencia de un emisor (consciente o no), un código y un receptor.

2. Artículo 10 de la Carta de Atenas de 1931. I Congreso Internacional de Arquitectos y Técnicos de los Monumentos Históricos (Atenas, 21-30 de octubre de 1931).

3. Artículo I de la Carta Internacional sobre la Conservación y Restauración de Monumentos y Sitios Carta de Venecia de 1964. "I Congreso Internacional de Arquitectos y Técnicos de los Monumentos Históricos. Venecia, 25-31 de mayo de 1964 (adoptada por IComos en 1965). 
También la Carta del Restauro de I972 reflexiona sobre la propiedad, por sí misma, de «un significado y valor» de la estructura urbanística de los centros históricos y la protección del contexto ambiental, «sobre todo cuando éste haya asumido valores de especial significado estrechamente unidos a las estructuras históricas tal como han llegado hasta nosotros» ${ }^{4}$. Es decir, que el objeto, al nutrirse de las relaciones que tejen la historia y la sociedad, se apodera de un motivo, de una razón de fuerza histórico-estética.

Otro ejemplo lo encontramos en la Carta de Burra de I999 donde se insta a «identificar y tomar en consideración todos los aspectos de su significación cultural» 5 en materia de conservación de Sitios del patrimonio cultural. Por consiguiente, la intervención sobre los objetos de Restauración estará condicionada por las denotaciones culturales (históricas, estéticas, técnicas, etc.).

No obstante, el objeto restaurado también adquiere un significado. Igualmente, es símbolo de unos valores determinados. Tanto el objeto restaurado (una vez intervenido) como el objeto de Restauración (aquel que es susceptible de serlo) comparten semejantes mecanismos de simbolización, y, aunque la intervención coadyuva a la función-signo del patrimonio cultural, la propia expresión de los trabajos de Restauración puede poseer la suya propia.

\subsection{MECANISMOS DE SIMBOLIZACIÓN}

Los procedimientos por los que los objetos patrimoniales actúan como símbolos son muy variados, aunque podemos describir las fórmulas más generales:

a. Mecanismos metonímicos. Se produce una relación que lleva a definir el todo por la parte: un elemento partícipe de un acontecimiento histórico pasa a representar al propio suceso, como ocurre con el Oratorio de San Felipe y las Cortes de Cádiz en la Constitución de i8ı2. También se genera una relación del autor por la obra (se interviene un Goya).

b. Mecanismos eufemísticos. Eupheme era la palabra que se utilizaba en el lugar de la que no debía manifestarse públicamente. Por extensión, las intervenciones sobre el patrimonio cultural pueden tener un carácter eufemístico tratando de sustituir aquello que no es afín a la estética imperante. No es extraño que el peso de los trabajos sobre los objetos culturales sean repintes, reconstrucciones, sustituciones de elementos, nuevos enlucidos, etc.

c. Mecanismos abductivos. Umberto Eco define la abducción como una inferencia, en la que «encontramos una circunstancia muy curiosa que podría explicarse por la suposición de que es el caso específico de una regla general, y, por tanto, adoptamos dicha suposición» ${ }^{6}$. La abducción se fundamenta en ordenaciones de

4. Anexo D de la Carta del Restauro de 1972

5. Artículo 5 del la Carta de Burra de 1999. Carta del ıсомos Australia para Sitios de Significación Cultural. Adoptada el 19 de agosto de 1979 y actualizada el 26 de noviembre de 1999.

6. Eco, Umberto: Tratado de semiótica general. Barcelona, Editorial Lumen, $5 .{ }^{a}$ edición, 2000, (año originario de publicación, 1976), p. 207. 
convenciones preconcebidas que interpreta circunstancias y contextos imprecisos. Dicha interpretación origina una convención cuando es aceptada socialmente produciendo nuevas raciones de códigos. La homogeneización de las intervenciones arquitectónicas muestra un proceso de abducción donde determinadas soluciones al contexto impreciso, que supone un monumento degradado, se admiten socialmente. Así se crea el respaldo al lenguaje actual de los trabajos de Restauración, adecuado o no.

d. Procesos de extracodificación. En la elaboración de signos, existe una dinámica entre fenómenos de hiper- e hipocodificación. En estos casos indeterminados, podemos hablar de forma genérica de extracodificación (categoría que comprende a ambos).

En primer lugar, mientras que un código establece significados a distintas expresiones mínimas, la hipercodificación regulariza el sentido de líneas más extensas: existe un código icónico que acepta la imagen de una mujer que lleva un par de pechos encima de una tabla o un bol, la hipercodificación iconográfica determina que dicha mujer describe a Santa Ágata. También ocurre cuando oímos piezas de compositores diferentes y se percibe algo que resulta «familiar», aún sin haber analizado más profundamente. Este es el proceso que se desarrolla cuando reconocemos la estética asumida de un objeto restaurado. Del mismo modo, se puede recorrer el camino inverso, es decir, reconociendo las reglas que codifican a un objeto como restaurado, se apliquen técnicas cortesanas como justificación del trabajo y que profundizaremos más adelante. Estaríamos en el caso de empleo de procedimiento globales de intervención sobre bienes culturales.

Por otro lado, se produce una hipocodificación cuando se admite una transmisión de contenido imprecisa, pero válida, aunque las reglas sigan siendo desconocidas. Este tipo de operaciones son las que se originan, por ejemplo, al visitar un país extranjero y se empieza a comprender que algunos comportamientos se relacionan con un significado genérico. A esta «aproximación» se denomina hipocodificación.

Este proceso es el que transcurre en las reconstrucciones cromáticas y volumétricas donde la documentación no es del todo precisa: de alguna manera nos acercamos al significado general del color o la forma. «Por tanto, si la hipercodificación avanza desde códigos existentes hasta subcódigos más analíticos, la hipocodificación avanza desde códigos inexistentes (o desconocidos) hasta códigos potenciales o genéricos» ${ }^{7}$.

\subsection{TAXONOMÍA DE VALORES SIMBOLIZADOS}

Se identifican los siguientes valores simbolizados, sin ser excluyentes, es decir, siendo susceptibles de estar presentes en un mismo objeto y para una misma persona. De esta manera, aunque los distintos valores se pueden solapar (por ejemplo, el valor religioso, de culto, de una iglesia del s. vi y su valor artístico por las peculiaridades

7. Eco, Umberto: op.cit., p. 213. 
del diseño del edificio) es necesario diferenciarlos porque corresponden a diferentes forma de conceptualizar los valores del patrimonio.

a. Valores metafísicos. Los valores de identidad grupal ${ }^{8}$ recogen las experiencias, hechos, entornos físicos o culturales capaces de hacer reconocerse como parte de un cuerpo común, al ser decisivos para el establecimiento de la identificación colectiva.

Los valores ideológicos, están presentes en muchos objetos patrimoniales. La religión o las convicciones políticas han utilizado estos medios para promocionar los principios y valores de los poderes que encarnan. Este hecho se hace especialmente patenten con las reacciones que causa cuando se agota el régimen que representan. Multitud de bienes de la iglesia católica fueron destruidos en la Guerra Civil española. También hemos podido ver en directo cómo se demolían los monumentos de dictadores en países de oriente próximo.

Los valores emotivos, personales, tienen la capacidad de rememoración para un sujeto o un colectivo muy pequeño como pueden ser muebles, fotografías, etc.

b. Valores socio-económicos. En un evidente sesgo económico que inunda la sociedad actual, el patrimonio cultural es entendido como un recurso más de aprovechamiento para la comunidad ${ }^{9}$. Sin embargo, se corre el riesgo de trivializar las intervenciones de conservación-restauración y de exponer conceptos ambiguos como «puesta en valor». Así, los valores económicos derivados de la conservación del patrimonio deben ser entendidos como un bien público.

c. Valores culturales. El Arte es un tipo de expresión altocultural que se simboliza por medio de sus artículos y a través de referentes históricos, es decir, de los objetos que evocan hechos culturales o aluden a sus practicantes más distinguidos. Así, una casa residencial granadina se repara mientras que la casa de Federico García Lorca se restaura. La carta recientemente descubierta de Albert Einstein, representa a Albert Einstein quien a su vez representa a la Ciencia, otro tipo de expresión altocultural.

La calidad artística atribuida es directamente proporcional a la capacidad cualitativa de simbolización, donde las obras maestra cumplen una mejor función simbólica del arte que una obra corriente. No obstante, la Restauración de los bienes culturales no depende del lugar que ocupen los mismos aunque en la práctica ejerce una presión estética.

Así, los objetos del patrimonio tienen la capacidad para transmitir, encarnar, o estimular una relación con el pasado. El valor histórico puede manifestarse de varias formas: desde la edad de los materiales constituyentes, de su asociación con personas o acontecimientos, de su singularidad, de sus cualidades tecnológicas, o de su potencial documental.

8. El Documento de Pavía: Preservación del Patrimonio Cultural: Hacia un perfil europeo del Conservador-Restaurador de 1997 considera que «el patrimonio cultural, tanto mueble como inmueble, es un componente fundamental de la identidad cultural europea, identidad que respeta las diversidades naturales y regionales».

9. Así se puede observar en los artículos 3 y 4 de la Carta de Quito de 1967, que insta a realizar acciones sistemáticas para poner en productividad una riqueza inexplotada mediante un proceso de revalorización, hasta colocar al patrimonio en condiciones de cumplir la nueva función a que están destinados. 
Hay dos subtipos importantes de valor histórico ${ }^{\mathrm{IO}}$ : por un lado, el valor educativo del patrimonio que radica en la posibilidad de adquirir conocimientos sobre el pasado a través de, por ejemplo, la arqueología o de la interpretación creativa de un artista del registro histórico encarnado en el patrimonio. Por otra parte, el valor artístico, basado en el hecho de: ser un objeto único; representativo de; ser el trabajo de un individuo en particular; etc.

Sin embargo, la complejidad de la evolución de los elementos básicos del patrimonio, como la definición de los objetos desde antigüedad hasta los bienes culturales, nos indica la variabilidad de los valores. Así, en la Carta de Cracovia, se define «patrimonio» como:

... el conjunto de las obras del hombre en las cuales una comunidad reconoce sus valores específicos y particulares y con los cuales se identifica. La identificación y la especificación del patrimonio es por tanto un proceso relacionado con la elección de valores. (Anexo. Definiciones)

Es decir, que reconoce que el patrimonio cultural y sus valores, además de ser variables, se formulan a partir de una fabricación intelectual de la comunidad, de la proyección que las personas hacen sobre los mismos. La Carta de Cracovia también se expresa en estos términos:

Los elementos individuales de este patrimonio son portadores de muchos valores, los cuales pueden cambiar en el tiempo. Esta variabilidad de valores específicos en los elementos define la particularidad de cada patrimonio. A causa de este proceso de cambio, cada comunidad desarrolla una conciencia y un conocimiento de la necesidad de cuidar los valores propios de su patrimonio. (Preámbulo)

\section{MUTACIONES EN LOS VALORES DE LOS OBJETOS DE RESTAURACIÓN EN LOS PROCESOS DE INTERVENCIÓN}

Los valores simbolizados en los objetos patrimoniales pueden desvirtuarse a lo largo de los distintos procedimientos y/o en la filosofía de intervención de Restauración.

Por ello, enumeramos las diversas transformaciones que afectan a los valores de los bienes culturales y que abarcan tanto a su materialidad como a su expresión como documento histórico (FIGURA I).

10. Mason, Randall: «Assessing Values in Conservation Planning: Methodological Issues and Choices», en DE LA TORRE, Marta (ed.): Assessing the Values of Cultural Heritage. Los Angeles, California, The Getty Conservation Institute, 2002, p 11. 


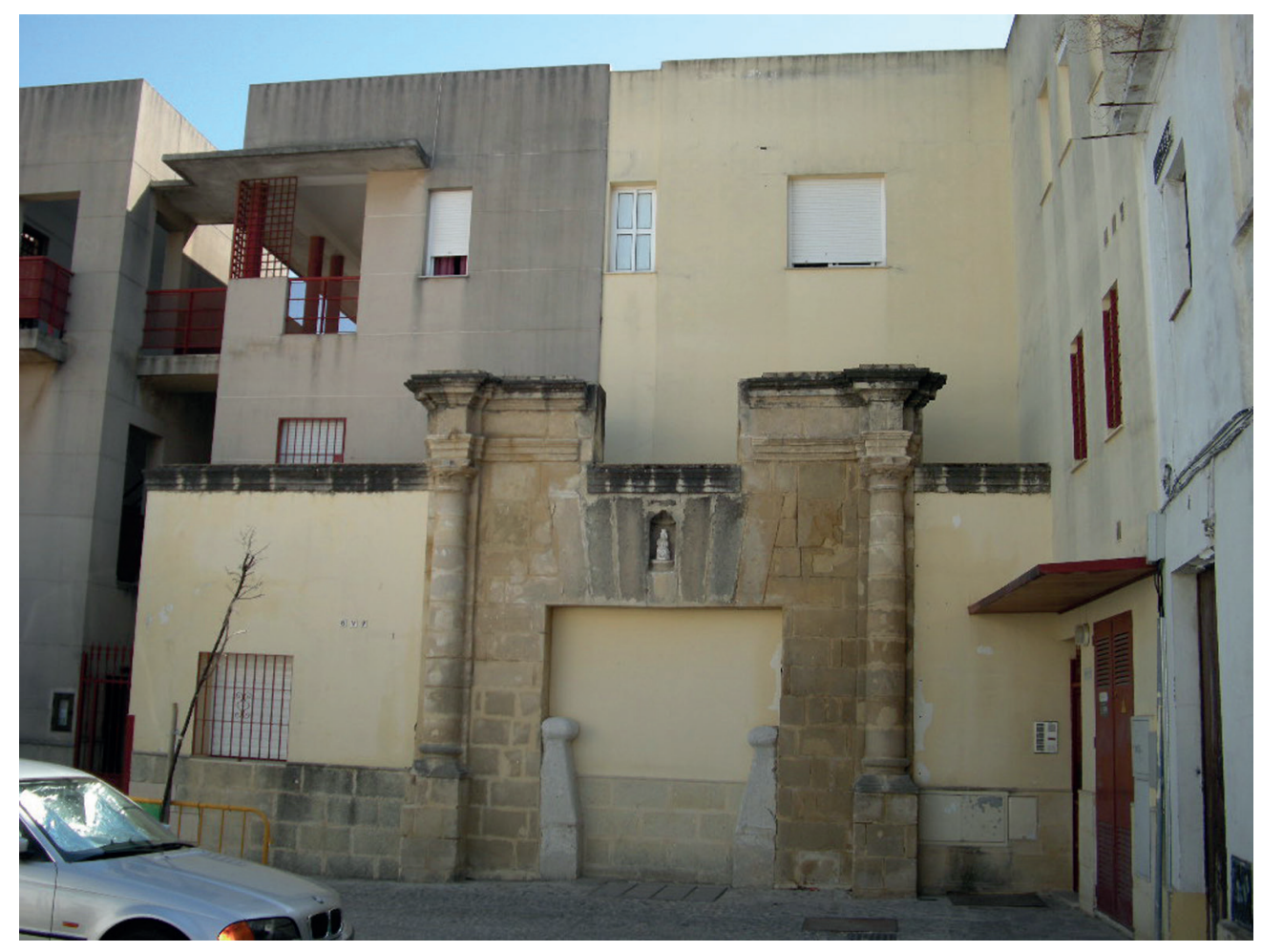

FIGURA 1. ILUSTRACIÓN DEL ALCANCE DE LAS MUTACIONES EN EL PATRIMONIO CULTURAL RELEGADO A MERA JUSTIFICACIÓN EN VIRTUD DE OTROS INTERESES

Autor: José Manuel Moreno Arana.

\subsection{EL VALOR DE LA EXPERIENCIA EXHIBIDA}

En la percepción de las obras de arte, intervienen dos valores: uno cultural, y otro,

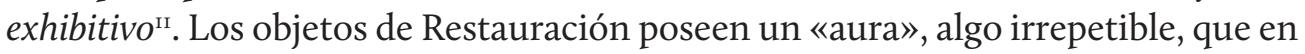
su extensión temporal nunca más se volverá a constituir y que al exhibirse se refleja en una dimensión real.

Así, «el acercarse espacial y humanamente a las cosas es una aspiración de las masas actuales (....), existe en ellos la necesidad de adueñarse de los objetos» ${ }^{\mathrm{r} 2}$. Ante esta premisa social, los objetos de Restauración consolidan su condición de mostrarse, sin preguntarse porqué se exhibe ni hacia dónde se exhibe, pero tonificando el mecanismo de valoración de la experiencia cercana. En dicha cercanía no se descubre al patrimonio cultural sino que se colecciona la eventualidad de la apropiación de la experiencia exhibida. Entonces, el aura se desgasta.

Además, no todos los bienes culturales fueron creados para ser mostrados públicamente. Muchos encargos en la historia del arte mantienen este carácter de uso y

11. Benjamin, Walter: Discursos interrumpidos I. Filosofía del arte y de la historia. Madrid, Taurus Ediciones, 1982 (año originario de publicación, 1972), p. 28.

12. Idem, p. 42. 


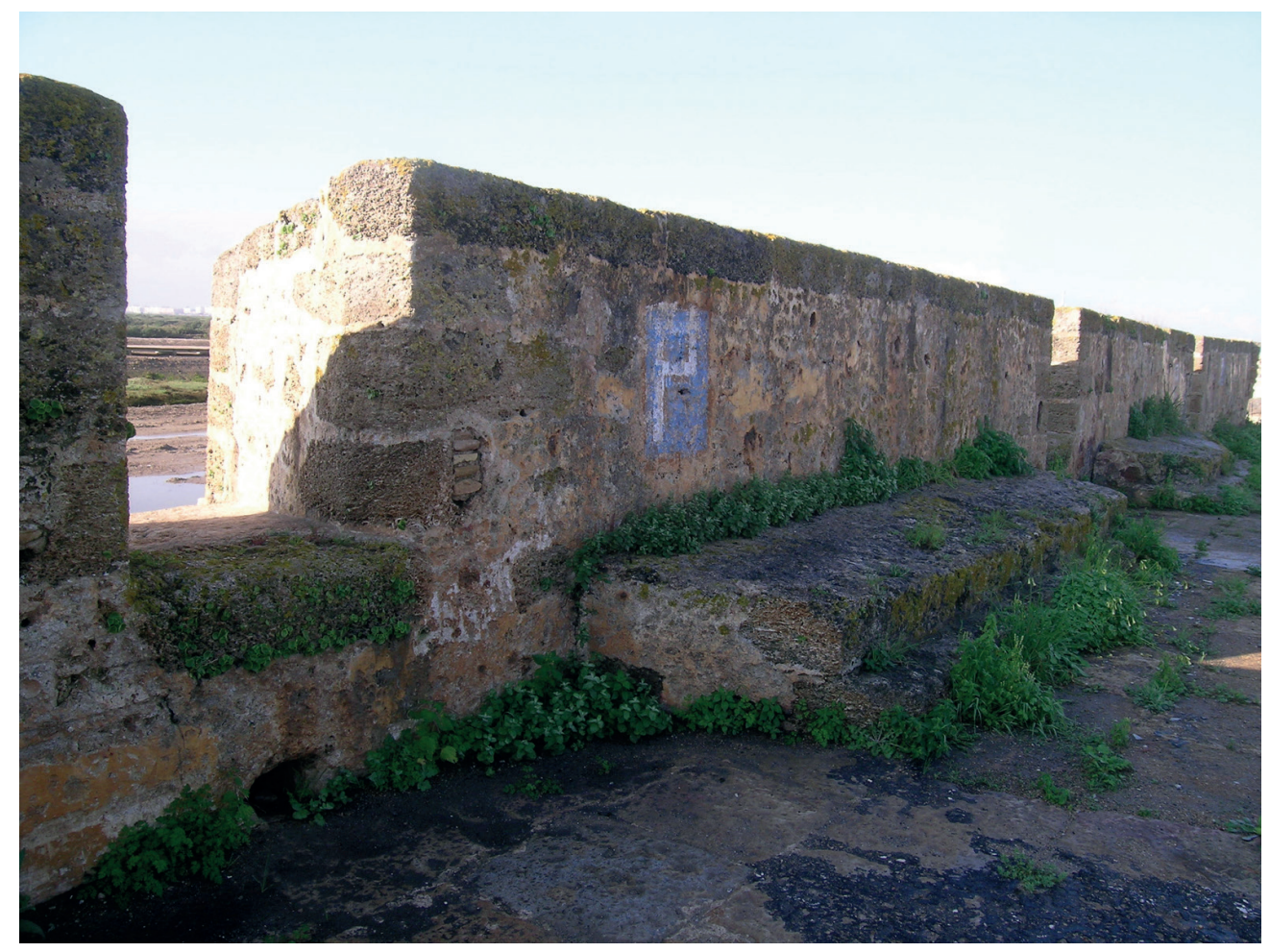

FIGURA 2. BATERÍAS DEFENSIVAS DEL S. XVIII USADAS COMO APARCAMIENTOS

disfrute privado. Pero, han crecido tanto las posibilidades de exhibición de la obra de arte, que desplaza a otros valores culturales, modificándolos fundamentalmente. De tal manera que la artisticidad se percibe más tarde y se reconoce como accesoria. Es el caso de los productos turísticos culturales donde se aprecia más la experiencia exhibida que la propia conciencia del documento histórico y su revelación estética.

\subsection{LA HEGEMONÍA DEL «VALOR DE CAMBIO»}

Apropiándonos de la filosofía marxista, introducimos los conceptos de «valor de uso», referido a las propiedades de utilidad para solventar una necesidad (desde las más biológicas hasta las espirituales), y el «valor de cambio», como valor cuantitativo, monetario de un objeto en el mercado.

El patrimonio histórico-artístico deja de ser autorreferencial cuando es consumido para ser valorado en una nueva producción, o cuando, de alguna manera, es vendido como producto. Así, pierde su «valor de uso», entendido como los valores intrínsecos de la obra, en pos de un «valor de cambio». Esta función «se mantiene y se cumple aún más plenamente en la situación en que desaparecen las obras individuales con su aureola en favor de un ámbito de productos relativamente 
sustituibles, pero de valencia análoga» ${ }^{13}$. Es el caso de los monumentos frente a otras tipologías como la pintura o la escultura, donde el carácter arquitectónico y su lenguaje material, permite una relativa sustitución de elementos en favor de la estática estructural.

Así, si se hace predominar el valor económico práctico, se corre el riesgo de que determinadas actividades que sólo pretenden maximizar los valores económicos terminen erosionando o desplazando a los valores históricos (tráfico de turistas, visitantes descuidados que toman fragmentos de recuerdo o escalan en ruinas...).

En este sentido, se puede decir, que existe un nuevo orden en la Restauración del patrimonio arquitectónico, en el momento de cambio de producto, en una visión materialista de la historia.

Sin embargo, el comportamiento económico no puede estar separado de la cultura porque la influencia de la lógica de los mercados está cada vez más presente en los ámbitos de la vida social. Además, lo económico y lo cultural representan dos actitudes/perspectivas muy distintas de cómo afrontar los valores y la valoración del Patrimonio ${ }^{\mathrm{I4}}$ (FIGURA 2).

En definitiva, el gobierno local es el único que puede actuar como contrapunto de los intereses privados que pueden no coincidir con los públicos, garantizar que todas las intervenciones se realizan de forma coordinada e indispensable para el lanzamiento, el diseño, la financiación y el mantenimiento de un proceso de conservación eficiente ${ }^{15}$.

\subsection{LA FETICHIZACIÓN DE LOS BIENES CULTURALES. LA RENTA SIMBÓLICA}

Profundizando en el cambio de valores anteriores, existe una correspondencia entre el contexto socioeconómico y la desvinculación del valor social de los bienes culturales. Podemos comprobar cómo la gestión del patrimonio se alinea con el dogma neoliberal, que lo entiende sólo como un recurso monetario rentable. Los inmuebles se concesionan con el argumento de continuidad del uso social de dicho patrimonio. A modo de ejemplo, presentamos algunas concesiones en la provincia de Cádiz, como la del molino de mareas del «Zaporito» ${ }^{16}$ en San Fernando,

13. Vattimo, Gianni: El fin de la modernidad. Nihilismo y hermenéutica en la cultura posmoderna. Barcelona, Ed. Gedisa, 2. ${ }^{a}$ edición (año originario de publicación, 1985), 1987, p. 58.

14. Mason, Randall: op. cit,. p. 10

15. RojAS, Eduardo: «Sustainable Preservation of the Urban Heritage. Lessons from Latin America», Conservation Perspectives. The GCI Newsletter: The Historic Cities. Volume 26, 2 (2011). The Getty Conservation Institute, pp. $10-13$.

16. Rivera, A.: «El empresario que explote el quiosco del Zaporito gestionará también su museo». Diario de Cádiz 31/08/2012 [en línea]. URL: http://WwW.diariodecadiz.es/article/sanfernando/1341627/empresario/explote/quiosco/ zaporito/gestionara/tambien/su/museo.htm/ [Consulta: 27/09/2012]; RıVERA, A.: «El Zaporito tendrá uso cultural y un restaurante en el entorno de la plaza» Diario de Cádiz 15/12/2011 [en línea]. URL: http://www.diariodecadiz.es/article/ sanfernando/1138561/zaporito/tendra/uso/cultural/y/restaurante/entorno/la/plaza.html [Consulta: 27/09/2012]. 
el Castillo de Sancti Petri ${ }^{17}$ en Chiclana de la Frontera o el Castillo de Santiago ${ }^{\mathrm{I} 8}$ en Sanlúcar de Barrameda.

Para J.A. Machuca ${ }^{19}$, la renta simbólica resulta del fenómeno de fetichización, que se fundamenta en la sugestión de los espacios de bienes culturales (en especial las zonas y sitios históricos y arqueológicos) como lugares de inversión privada en el campo comercial y de servicios. Es decir, el aprovechamiento económico de los bienes culturales por la calidad y la atracción especial que ejercen sobre el turismo.

De esta forma, estos edificios rehabilitados que se dedican a las actividades de turismo y recreación, deprimen otros usos y merman la diversificación: tanto la demanda de propiedades en el centro histórico como la mezcla de habitantes y usuarios (se desplaza a la mayoría de los residentes originales que no pueden regresar debido al aumento de los precios de alquiler) ${ }^{20}$.

El carácter excepcional y único de los objetos culturales es un aspecto de la fetichización que se refiere a la condición extraordinaria, intocado, exclusivo, tan atrayente para el mercado. En este caso, «ya no se antepone la propiedad de la nación sobre los bienes culturales, ésta pasa a un segundo plano o se coloca como un principio abstracto (metasocial) que no tiene referencia con las formas concretas de propiedad y usufructo privados ${ }^{2 \mathrm{I}}$.

El punto de vista más frecuente, se postula en contra de su comercialización dentro de la lógica del mercado pues se produce un flujo unidireccional y termina pareciéndose a un imperialismo cultural ${ }^{22}$.

Así, existe una falta de envidia del pasado frente a la que se tiene del futuro. Cuenta más la proyección económica del bien cultural como producto, las prebendas que se puede extraer de él que la expresión material y espiritual del testimonio del pasado. La Restauración tiene más de conmemoración que de quiromancia, sin embargo, la necesidad de rentabilización política y económica, la falsa idea de progreso, la ambigüedad del término puesta en valor, la falta de formación y la escasa pedagogía profesional, dejan al patrimonio cultural a merced de las leyes del mercado y la reducción de sus valores hacia un mero producto de consumo.

Este realismo del qué-más-da normaliza, a falta de criterios estéticos, la posibilidad y la utilidad de comparar el valor del patrimonio cultural con el ingreso que se puede sacar del mismo. Además, esta realidad tiene una capacidad de adaptación a cualquier tendencia, siempre y cuando ésta tenga poder de compra.

17. Rivera, A.: «El Castillo de Sancti Petri se queda sin visitas guiadas y sin vigilancia». Diario de Cádiz 25/O1/2012 [en línea] URL: http://www.diariodecadiz.es/article/provincia/1167654/castillo/sancti/petri/se/queda/sin/visitas/guiadas/y/sin/vigilancia.htm/ [Consulta: 27/o9/2012]; RıverA, A.: «El Castillo es para el verano». Diario de Cádiz 25/O1/2012 [en línea]. URL: http://www.diariodecadiz.es/article/provincia/1275977/castillo/es/para/verano.htm/ [Consulta: $06 / 06 / 2012]$.

18. HiniestA; L.: «Castillo de Santiago». Diario de Cádiz 14/04/2009 [en línea]. URL: http://www.diariodecadiz. es/article/opinion/398543/castillo/santiago.htm/ [Consulta: 27/09/2012].

19. Machuca R., Jesús Antonio: «Percepciones de la cultura en la posmodernidad». Alteridades, 16 (1998), p. 36.

20. RojAS, Eduardo: op. cit., p. 12.

21. Machuca R., Jesús Antonio: Ibidem, p. 36.

22. VoudourI, Daphne: «Law and the politics of the past: Legal protection of cultural heritage in Greece», International Journal of Cultural Property, Volume 17, 3 (2010), p. 566. 


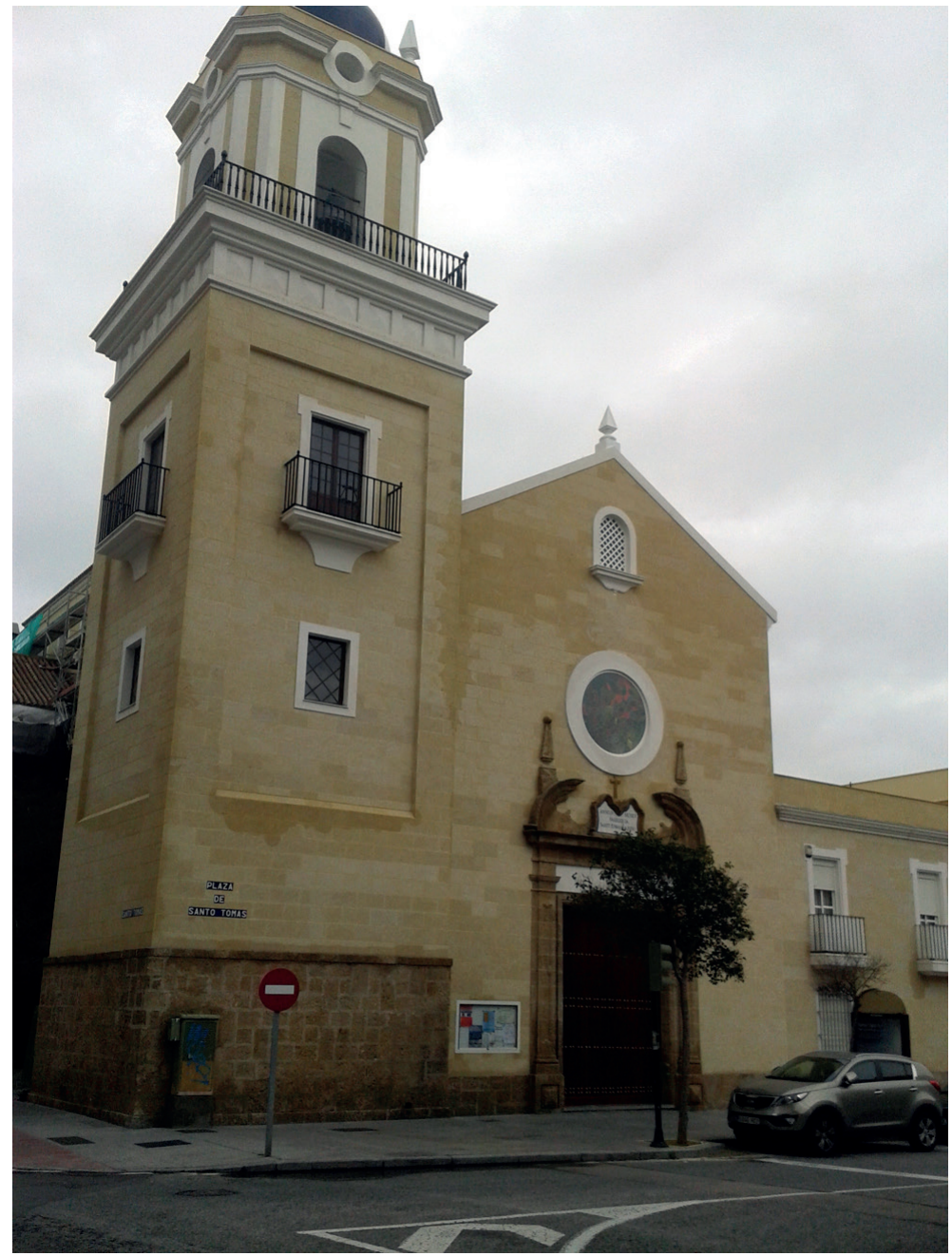

FIGURA 3: OBRAS DE REVESTIMIENTO DE PLACAS PÉTREAS CONTEMPORÁNEAS CON EL OBJETIVO DE BUSCAR UNA MAYOR EFICACIA

EN LA CONSERVACIÓN DEL EDIFICIO.
Por otro lado, en un proceso que irónicamente relega a la propia cultura que oferta, el desarrollo del turismo se ha convertido en promotor de una anticultura. Para contrarrestarla será necesario: el desarrollo de una fuerte teoría cultural, programas de educación, creando un conocimiento más profundo del valor del patrimonio cultural, y la reinvención del museo, del patrimonio restaurado, del monumento, o cualquier otra representación de la memoria colectiva ${ }^{23}$.

\subsection{LA INTOXICACIÓN FUNCIONALISTA}

En los fenómenos de la Restauración arquitectónica, se produce una aproximación a la doctrina funcionalista, que, aunque sus principios se refieren a construcciones de nueva planta, contaminan los criterios de intervención edilicia de carácter histórico.

Enunciado por L.H. Sullivan, que afirma en su célebre frase «la forma sigue siempre a la función», la corriente funcionalista defendía que el diseño arquitectónico debe estar basado en el propósito del edificio. La forma se sintetiza como vehículo para obtener la función. Es un simple agente. El precedente del funcionalismo arquitectónico es Vitruvio, inspirado en el trinomio utilitas (comodidad o utilidad), venustas (belleza) y de firmitas (solidez) como las claves clásicas de la arquitectura.

Así, los proyectos de Restauración arquitectónicos se ven influenciados por la doctrina funcionalista. Entendida ésta como una «reafirmación de los valores puramente arquitectónicos (espacio, volumen...) frente a los pictórico y escultórico

23. MacCanNeLL, Dean: «Cultural Tourism», Conservation. The Getty Conservation Institute Newsletter. Volume 15,1 (2000), p. 26. 
(tratamiento superficial de muros, decoraciones...) que habían invadido el campo de la arquitectura $»^{24}$.

No obstante, la arquitectura también posee una función íntimamente ligada a la idea de significado. De esta forma, los maestros modernos trataron de abandonar los convencionalismos. Encontraron en la «novedad» la manera de huir del uso social establecido. La necesidad de lo «nuevo» condujo a identificar la utilización de referentes como una falta de competencia creativa ${ }^{25}$ (FIGURA 3).

También, la arquitectura se concebía como un reflejo de un estado objetivo. Para Mies, «nuestros edificios utilitarios merecerán el nombre de arquitectura solamente si interpretan fielmente nuestros tiempos ${ }^{26}$.

Por otro lado, Frank G. Matero ahonda en la Teoría de la Restauración y reconoce la necesidad de contar con enfoques relativos a la restauración en función de si el trabajo está dirigido sobre una arquitectura «industrial» o concebida como «arte» ${ }^{27}$. En el primer caso, predominan los objetivos funcionales, mientras que en el último caso, la dualidad estética e histórica guía la intervención de la obra, es decir, que los requisitos funcionales serían secundarios respecto a los valores estético-histórico. Así, la conservación de monumentos exige soluciones diferentes a otras tipologías de obras de arte por estar unidos a su contexto y sujetos a requisitos específicos ambientales y funcionales.

Todas estos conceptos de arquitectura impregnan la intervención monumental, produciendo una contaminación cuando no se es capaz de abordar el problema de la Restauración desde el antecedente de la doble polaridad, histórica y estética, de la obra de arte.

\subsection{SIINDROME DE LA ARQUITECTURA PARAHISTÓRICA ${ }^{28}$}

El patrimonio arquitectónico, formado no sólo por el monumento sino por la noción más compleja de conjunto histórico, es «un capital espiritual, cultural, económico y social con valores irremplazables $»^{29}$. Su pérdida supondría la privación de una parte de la conciencia colectiva. Asimismo, todos los bienes culturales son únicos e irrepetibles, y, por tanto, es necesario asumir este carácter singular para que su conservación sea compatible con su uso.

24. Perelló, Antonia M.: Las claves de la arquitectura. Barcelona, Editorial Ariel, 1987, p. 13.

25. BONTA, Juan Pablo: Sistemas de significación en arquitectura. Un estudio de la arquitectura y su interpretación. Barcelona, Editorial Gustavo Gili, 1977, pp. 46-62.

26. BonTA, Juan Pablo: op. cit., p. 60.

27. Matero, Frank G.: «Loss, Compensation, and Authenticity: The Contribution of Cesare Brandi to Architectural Conservation in America», Future Anterior. Volume IV, I (2007). Graduate School of Architecture, Planning and Preservation. Columbia University.

28. SÁNCHEZ FERNÁNDEZ, Antonio J.: «Semiología clínica de la restauración monumental: síndrome de la arquitectura parahistórica», ASRI: Arte y Sociedad. Revista de Investigación, 1 (2012). Eumed.net, Universidad de Málaga [en línea]. URL: http://asri.eumed.net/1/ajsf.pdf [Consulta: 19/02/2012].

29. Artículo 3 de la Carta Europea del Patrimonio Arquitectónico de 1975 en Consejo De Europa. Carta Europea del Patrimonio Arquitectónico de 1975 [en línea]. URL: http://www.mcu.es/patrimonio/docs/MC/IPHE/Biblioteca/ AMSTERDA.pdf [Consulta: 19/12/2011]. 


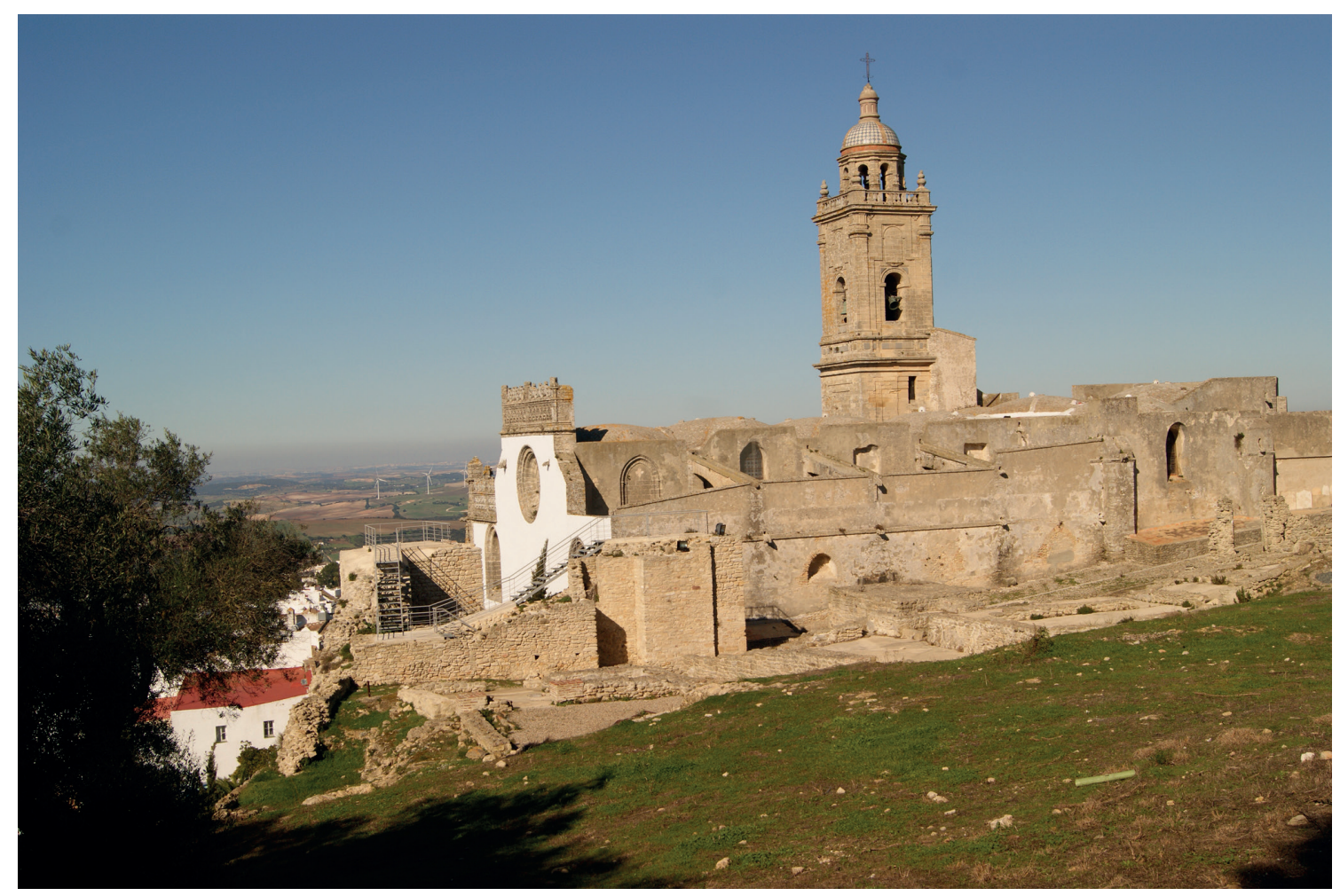

FIGURA 4. IGLESIA S. XVI-XVII

Intervenciones inadecuadas que introducen falsificación histórica y estética.

Pero existen, además, otros peligros que atentan contra la suma de características sustanciales, históricamente determinadas del patrimonio arquitectónico. A pesar de la presencia de las Cartas y Documentos internacionales y de las normativas de rango legal, es continuo observar cómo el producto de los trabajos de restauración en el patrimonio inmueble pasa por intervenciones inadecuadas que ignoran la dualidad obra de arte-documento y la conciliación de la instancia histórica y la estética.

Como secuela de esta indolencia aparecen subproductos culturales como simulacro de patrimonio arquitectónico pero despojado de todos los valores rememorativos, descrito por Aloïs Rieg ${ }^{30}$, que reflejan el reconocimiento del monumento como algo que pertenece al pasado.

El quebranto de estos valores nos muestra una arquitectura "parahistórica»: unos valores edilicios al margen de la Historia o en contra de la misma.

Tras el pinchazo del boom inmobiliario de las últimas décadas, algunas empresas constructoras han buscado nuevos nichos de mercado «rehabilitando» $\mathrm{y}$ «restaurando» nuestro patrimonio arquitectónico. Pero esta mentalidad empresarial se

30. Riegl, Aloïs: El culto moderno a los monumentos. Madrid, La Balsa de la Medusa, 3. ${ }^{a}$ edición, 2008, (año originario de publicación, 1903), pp. 47-68. 
encuentra distanciada de los criterios actuales de intervención y es insensible a los valores intangibles de los edificios históricos. El efecto: la invención de una falsa historiografía estetizante (FIGURA 4).
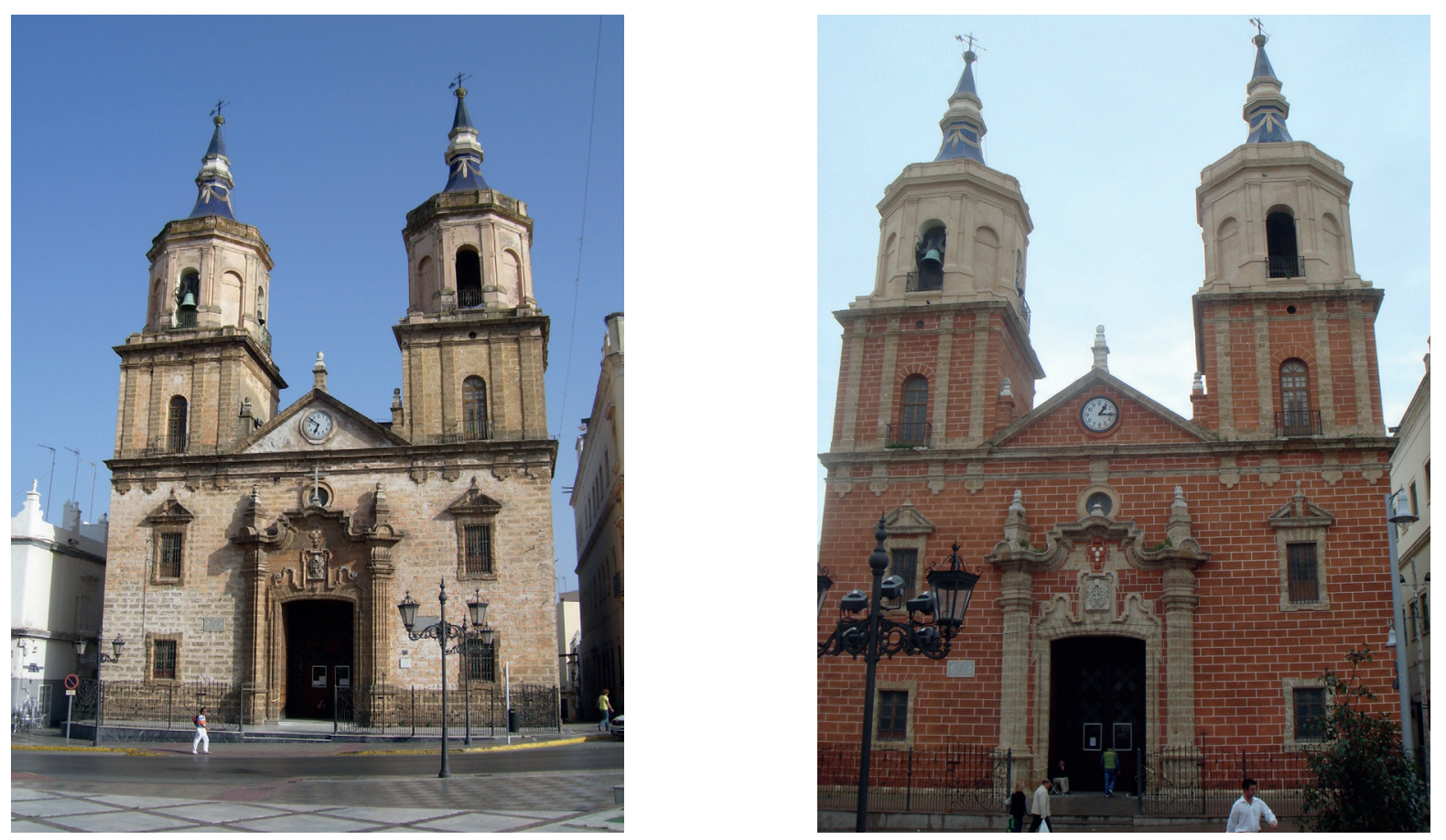

FIGURAS 5 Y 6.

Antes y después de la intervención sobre un edificio del siglo xvIII, donde se han eliminado los valores históricos que se encuentran traducidos en la pátina natural de los materiales, bien por una excesiva limpieza bien por una descomunal reintegración cromática. Autor figura 5: Pablo Jones. Autor figura 6: Xemenendura.

En concreto, se está produciendo una asociación estética producto de esta invasión inmobiliaria que se ha interiorizado en la conciencia social. Es el monumento el que se está adaptando a las exigencias estéticas que lo rodea y no al contrario. Así, el patrimonio construido queda anulado por la expresión arquitectónica contemporánea que dinamita irremediablemente el potencial expresivo de las obras edilicias. Estas hiperintervenciones producen un gran contraste en la imagen resultante, con una violencia gráfica sólo anestesiada por el valor de novedad, arriba mencionado.

En este sentido, se observa la falta de adecuación de la Restauración a las implicaciones temporales sobre la obra de arte, que ya Cesare Brandi analizó ${ }^{31}$ e identificó en tres momentos ${ }^{32}$.

31. Brandi, Cesare: Teoría de la restauración. Madrid, Alianza Editorial, 2. ${ }^{a}$ edición, 2002, (año originario de publicación, 1963), p. 29

32. En conexión con los tres momentos estructurales ruskinianos que marcan la vida de los edificios: el inicio, la creación; el funcional, el uso y el momento de la conservación. 
No obstante, se da el caso en el que un edificio se «complementa» con partes no documentadas ni decididas por un equipo multidisciplinar, como respuesta a un ejercicio autónomo de interpretación que da como resultado un falso histórico y estético. Una idea mal entendida de belleza que es incompatible con el respeto a las imperfecciones y alteraciones que se hayan convertido en parte de la historia de la edificación.

En definitiva, «la intervención debe responder a un plan integral de conjunto que tenga debidamente en cuenta los diferentes aspectos de la arquitectura, la estructura, las instalaciones y la funcionalidad $»^{33}$. Además, «debe respetar, en la medida de lo posible, el concepto, las técnicas y los valores históricos de la configuración primigenia de la estructura, así como de sus etapas más tempranas» ${ }^{34}$ (FIGURAS 5 y 6).

La restauración tampoco puede ubicarse en la horquilla temporal entre la conclusión de la obra y el presente. Es la llamada restauración de repristino o estilística, que intenta eliminar este lapso de tiempo al pretender recuperar la obra de arte en su estado original. Para Brandi, la restauración no debe abolir las modificaciones naturales o las debidas a la acción humana de las obras de arte que el transcurso de la historia ha impreso en ellas.

Esta fase es en la que se concentra la mayoría de las intervenciones actuales. Los deterioros ya producidos son considerados datos de importancia documental para el valor histórico, pero el imaginario colectivo y el horizonte de expectativas de algunos profesionales, no acepta el estado imperfecto, la carencia de carácter cerrado o la tendencia a la erosión de forma y color que el patrimonio histórico adquiere con el tiempo. Se pretende erradicar ese lapso de tiempo. En palabras de Aloïs Riegl35:

(...) desde siempre, el valor de novedad ${ }^{36}$ ha sido el valor artístico de las grandes masas, de los que poseen poca o ninguna cultura, frente a lo cual, el valor artístico relativo ${ }^{37}$, por lo menos desde el comienzo de la Edad Moderna, sólo ha podido ser apreciado por los que tienen formación y cultura estética. A las masas les ha complacido desde siempre lo que se mostraba de modo evidente como algo nuevo. Siempre se ha deseado ver en las obras humanas la victoriosa acción creadora de la fuerza del hombre y no la influencia destructora de las fuerzas de la naturaleza, hostil a la obra humana. Sólo lo nuevo y completo es bello según las ideas de la masa; lo viejo, fragmentario y descolorido es feo.

33. Artículo 3.13 de los Principios para el Análisis, Conservación y Restauración de las Estructuras del Patrimonio Arquitectónico de 2003, en Icomos, op. cit.

34. Artículo 3.12 de los Principios para el Análisis, Conservación y Restauración de las Estructuras del Patrimonio Arquitectónico de 2003, en Icomos, op. cit.

35. Riegl, Aloïs: op. cit., pp. 80-81.

36. El valor de novedad es el que hace referencia a la apariencia cerrada, acabada, sin deterioro de las obras de arte.

37. El valor artístico relativo se refiere a aquella parte de la creación artística antigua que puede ser apreciada por la sensibilidad moderna. 
No se trata de la conformidad poética-pintoresca ruskiniana pero tampoco de la pretensión de hacer reversible el tiempo o reproducir a voluntad la obra de arte.

\subsection{LA IRREMEDIABILIDAD COMO COARTADA}

En el mecanismo de modernización existe una aceptación de una posible pérdida irremediable.

En ocasiones, en el campo del patrimonio cultural, el interés socioeconómico se opone con la salvaguarda de bienes ${ }^{38}$, pues el interés particular de determinadas políticas patrimoniales, no coinciden con el interés general (FIGURA 7).

Existe una posición extrema que determina la imposición de un ideal de modernización. Con el pretexto de aspecto perecedero del patrimonio cultural se legitiman vagamente concepciones y trabajos de intervención sobre bienes culturales.

En definitiva, como nada es eterno, se puede eliminar o, en el mejor/peor de los casos, integrar los restos para apoyar a lo moderno.

\subsection{LA PERFORMANCE TECNOCIENTIIFICA}

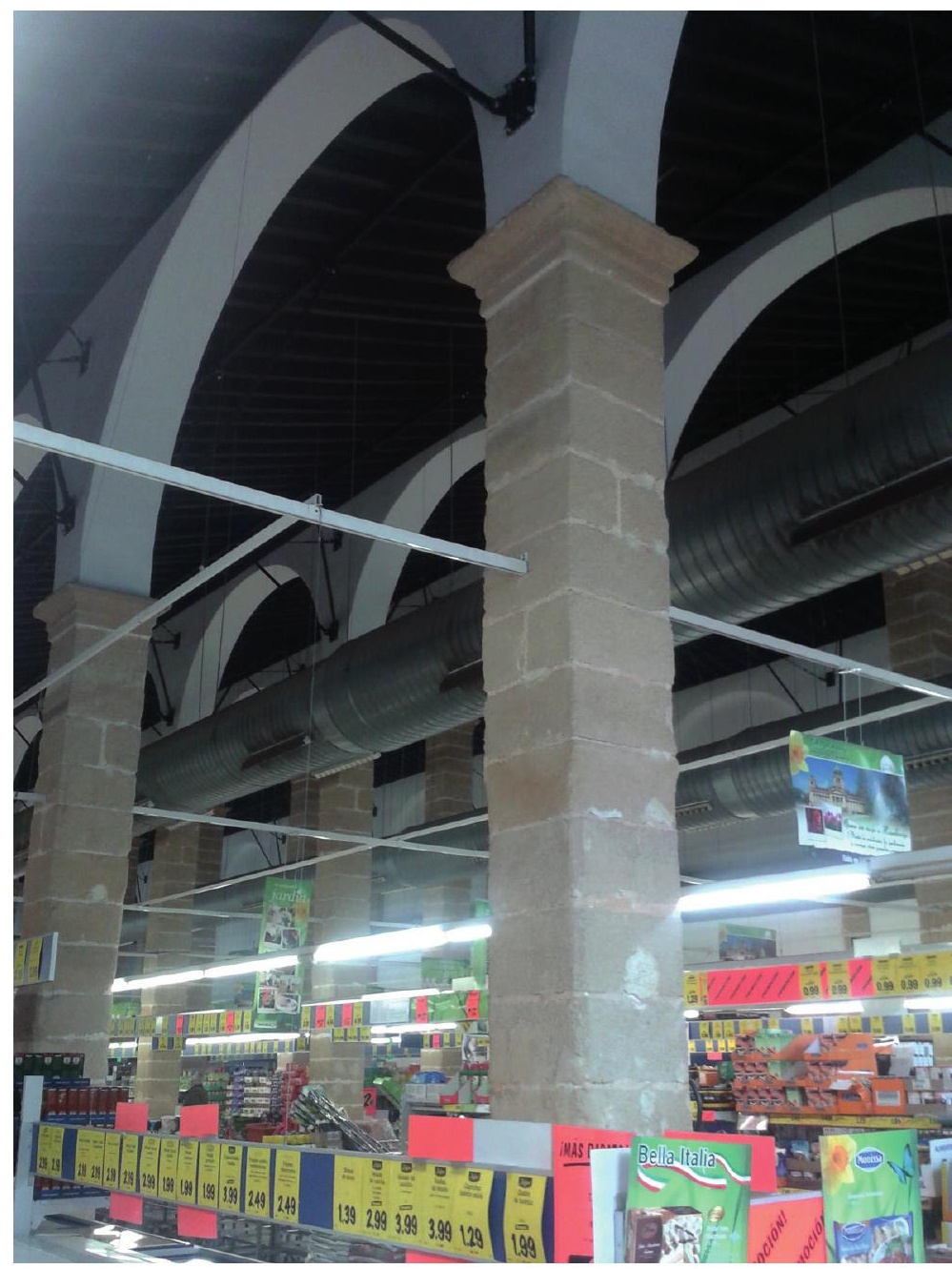

FIGURA 7. REUTILIZACIÓN DEL PATRIMONIO INDUSTRIAL BODEGUERO (S. XIX) Y SU DESCONTEXTUALIZACIÓN EN EL SECTOR SERVICIOS.

En la sociedad contemporánea, el criterio tecnocientífico subordina y envuelve las formulaciones del conocimiento.

No obstante, la investigación científica ha permitido saber con exactitud cómo era un objeto en un momento concreto, qué mecanismos de alteración se está produciendo (corrosión, sulfatación, carbonatación, etc.), pueden determinar qué

38. Es el caso del yacimiento arqueológico de Cercadilla ubicado en Córdoba. Los restos fueron descubiertos en 1991 por las obras de soterramiento del ferrocarril y construcción de la estación del AVE de la ciudad. Buena parte de su superficie se encuentra oculta o destruida. Aunque la imagen que Cercadilla pretende ofrecer es la de superposición de la ciudad moderna y la extensión del yacimiento bajo ella, adquiere el significado del atropello del falso ideal de progreso e intereses monetarios. 
procesos de Restauración son más adecuados (consolidación/hidrofugación pétrea, limpieza de barnices, etc.), además de controlarlos.

Pero, a la evidencia de que todos los objetos patrimoniales son objetos materiales y reducir la Restauración a esta visión, es simplificar esta cuestión hasta negar la propia naturaleza de los objetos culturales. La tecnociencia no puede ser la disciplina definitiva que abarque las contingencias de la Restauración, pues los objetos histórico-artísticos poseen valores metafísicos que les son inherentes.

La incuestionabilidad de las leyes físico-químicas eclipsa la reflexión teórica, apartando el examen ético o estético. La ciencia informa, pero no debe negar el juicio de los criterios de intervención y mucho menos empequeñecer a los valores intangibles.

\section{RESTAURACIÓN Y SIGNIFICACIONES ARQUITECTÓNICAS}

Aunque la Restauración del patrimonio cultural debe equivaler a una intervención aséptica, se ha de aceptar la imposibilidad de «no expresar». Es decir, ser aséptico no es igual a carente de significado. Por definición, una obra histórico-artística no significante, no pertenecería al campo de la cultura. De la misma forma, la intervención en materia de Restauración, no debe carecer de significado, es más, su significado es no significante: es el vehículo para transmitir la estructura histórica.

Puede existir disparidad entre lo que un monumento arquitectónico es y lo que significa para un individuo que podrá manifestar opiniones concernientes a la función del edificio y sus efectos sobre sus usuarios, o acerca de los valores reflejados en el diseño, así como su significación histórica o sus connotaciones ideológicas. Entonces, estamos reflejando la realidad cultural, no sólo la realidad física de la arquitectura.

La clave de la semiótica es la distinción entre lo que una forma es y lo que significa para un cierto grupo social. Por este motivo, buscamos el comportamiento de los signos tanto en los objetos histórico-artísticos como en las intervenciones de Restauración sobre los mismos. El objeto de esta óptica pasa por evitar la ceguera ante la distinción entre forma y significado; la percepción y aceptación de la diferencia, y, finalmente, el reconocimiento de que la distinción es esencial si la arquitectura ha de volverse un elemento patrimonial de la cultura humana.

\section{RESTAURACIÓN Y SIGNIFICACIONES DEL PATRIMONIO MUEBLE. FIGURATIVIDAD E ICONICIDAD}

Todos los bienes culturales son portadores de un significado. La pintura o escultura, por ejemplo, ya sea figurativa o abstracta, trata «sobre algo»: es una afirmación acerca de la naturaleza de nuestra existencia ${ }^{39}$, es decir, hacen referencia a un elemento

39. Arnheim, Rudolf: Arte y percepción visual. Madrid, Alianza Forma, $14 .^{a}$ reimpresión, 1997, (=1979), p.78. 
del mundo natural. Este enunciado es la respuesta a cómo las figuras producen un efecto de «realidad». Entonces, cuando el espectador mira, se produce una actualización que sedimenta los significados constituidos.

Este discurso figurativo reviste la eficacia icónica de las representaciones, y que, en materia de Restauración de bienes muebles ha protagonizado la línea de flotación de las intervenciones. También la imagen de las intervenciones produce un efecto de «realidad», que aprovechando el discurso de la figuratividad alcanza el grado de iconicidad. Es decir, el efecto icónico de las intervenciones resulta de una fijación por referenciación de sus rasgos.

\section{LA INFLUENCIA DE LOS MEDIOS DE COMUNICACIÓN SOCIAL EN LA RESTAURACIÓN DEL PATRIMONIO CULTURAL}

Actualmente, los ámbitos de las artes plásticas en general están vinculados al mundo de los medios de comunicación de masas y su traducción al lenguaje de las imágenes. De igual manera, la Restauración del patrimonio también se encuentra bajo en el influjo de los mass media.

Así, la experiencia estética de la obra de arte se apoya en el concepto de «percepción distraída» introducido por Walter Benjamin, por el cual el espectador ya no aprecia «obras», tras la caída del aura que integra todo objeto artístico, sino que encuentra significaciones.

De la misma forma, se ha caído la aureola del patrimonio como documento y como objeto perteneciente al pasado para convertirse en un mero objeto mercantil y como vehículo o escenario artificial ${ }^{40}$. Al transformar las relaciones entre la sociedad y el patrimonio, las significaciones de éste mutan hacia los valores de actualidad proclamados por Aloïs Riegl ${ }^{41}$, y se van distanciando de las implicaciones temporales o aquellas características que hacen a un objeto representativo de una determinada etapa histórica y/o artística.

La influencia de los medios de difusión de masas en la sociedad actual ha alcanzado cotas únicas en la historia. Además de proporcionar información, cultura, entretenimiento, en un atractivo paquete de productos, producen consenso, instauración e intensificación de un lenguaje común en lo social ${ }^{42}$. Es decir, el impacto de la técnica en el sentido descrito por Benjamin anteriormente, se presenta como un hecho que establece una manera de generalización de lo estético, en nuestro caso, en relación con la dimensión histórico-estética del patrimonio cultural.

Pero, la influencia de la reproductibilidad técnica no sólo se puede poner de manifiesto en las redes de los medios de comunicación de masas. Los nuevos materiales

40. No presentamos aquí una crítica exclusiva de la mercantilización de la obra de arte, sino cómo las intervenciones sobre el patrimonio, en especial el arquitectónico, se ponen al servicio de nuevas acepciones de los valores patrimoniales a menudo ligadas al concepto de progreso y rentabilización económica.

41. RIEGL, Alö̈: op. cit., pp. 71-72.

42. VAtTimo, Gianni: op. cit,. p. 52. 
y la ampliación de posibilidades han permitido la proliferación de reconstrucciones tanto volumétricas como cromáticas.

No obstante, incluso en las mejores reconstrucciones, falta algo: el aquí y ahora de los objetos patrimoniales, su existencia única en el lugar en que se encuentran. Además, en esta singularidad se adjuntan determinadas alteraciones materiales que los identifican como piezas propias del pasado. En determinadas ocasiones las reconstrucciones de una obra de arte pueden dejar íntegra su consistencia formal, sin embargo, relegan a un segundo plano su aquí y ahora, su autenticidad, entendida como el sumando de todo lo que acontece a una obra a lo largo del tiempo.

La reproducción se desvincula del ámbito de la tradición, su presencia se aleja del carácter irrepetible de la obra de arte y confiere actualidad a lo reproducido. Todos estos procesos conducen a una fuerte conmoción de la tradición.

A la instantaneidad de la verdadera imagen del pasado se le hace frente con la actuación sobre la imagen actual de los objetos pertenecientes al pasado. Respetando todos aquellos indicativos visuales que los cataloga como tales.

Desde esta maniobra de consentimiento, el patrimonio cultural sólo habla callando y la experiencia estética no se da sino como negación de todos aquellos caracteres que habían sido canonizados en la tradición ${ }^{43}$.

\section{PERCEPCIÓN VISUAL DEL PATRIMONIO CULTURAL. HACIA UNA GENERALIZACIÓN DE LO ESTÉTICO}

\subsection{CONCEPTOS GENERALES}

Para comprender hechos que no son perceptibles directamente, necesitaremos otros que sí lo sean, es decir, un INDICADOR (ver TABLA I). En este sentido, las señales son un tipo especial de indicadores que además de ser usadas de forma intencionada, también el receptor que interpreta dichas señales se percata de que se usan a propósito para comunicar algo. Toda señal será un indicador, pero no todo indicador constituye una señal, pues debe cumplir los dos requisitos anteriores. Por otro lado, cuando un indicador no se utiliza de forma deliberada, lo llamaremos indicio.

TABLA 1. TIPOS DE INDICADORES

\begin{tabular}{ccc} 
Intencionalidad del emisor & $\begin{array}{c}\text { RECEPTOR SUPONE } \\
\text { INTENCIONALIDAD }\end{array}$ & $\begin{array}{c}\text { RECEPTOR NO SUPONE } \\
\text { INTENCIONALIDAD }\end{array}$ \\
\hline No intencionalidad del emisor & Señal & Indicio intencional \\
Mseudoseñal & Indicio
\end{tabular}

43. Vattimo, Gianni: op. cit., p. 14 . 
En definitiva, existen dos tipos de indicadores ya sean deliberados o no: las señales, que comunican, y los indicios, que indican. Sin embargo, ambos expresan algo.

También puede existir otra posibilidad combinatoria, esto es, indicios usados conscientemente para comunicar una cuestión, que no son advertidos como tales por el receptor, hablamos entonces de indicios intencionales.

Por ejemplo, ocurre en los estilos artísticos, que ciertos rasgos formales, colores, materiales, etc., se asocian a la vanguardia. Es más, ciertas maneras de vestir, actuar, hablar, se relacionan con grupos profesionales (artista), ideologías... En primera instancia, nos encontramos con indicios que muestran la pertenencia de una obra a la vanguardia artística, o de un individuo a un grupo social. Pero, conocido este mecanismo se puede reproducir estos indicadores de manera intencionada, induciendo la idea que interese. Se produce una dinámica en el sistema de significación.

Esta manipulación se extiende a la Restauración, determinadas intervenciones se realizan con la intención de provocar una cierta impresión en el espectador. Al ajustarse a la estética establecida, se acata la norma del grupo y la aceptación de sus valores.

Por último, hay indicadores que el receptor supone que han sido utilizados premeditadamente para comunicar algo, sin que esto haya sido ciertamente así: son las pseudoseñales.

El sentido de los indicadores, al margen de si son señales o indicios, está condicionado por la dimensión cultural. La génesis del indicio se encuentra en la realidad misma que quedará sesgada en el momento de su interpretación por el individuo en una operación cultural, regida por una matriz social de posibilidades y restricciones ${ }^{44}$.

\subsection{CINÉTICA EN SISTEMAS DE SIGNIFICACIÓN. EL RIESGO DE CONVENCIONALIZACIÓN DE LA RESTAURACIÓN}

La metamorfosis de los sistemas de significación en el arte es constante. Determinadas formas que se elaboran como indicios en un momento dado, pueden mutar en indicios intencionales, señales o pseudoseñales.

Estos movimientos pueden acarrear consecuencias en dichas formas: continuando intactas o variando, depurándose o volviéndose toscas. También puede variar el significado de dichas formas.

Así, podemos describir un trazado que va desde el indicio, del que parte el indicio intencional y que, en un proceso de convencionalización, surge la señal.

De esta manera, la conducta o la forma queda ligada a un significado acostumbrado que el receptor lo identificará inmediatamente aunque se transforme gradualmente simplificando o distorsionándose. Es decir, el proceso de convencionalización

44. BonTA, Juan Pablo: op. cit., p. 38. 
tiende a provocar a largo plazo una estabilidad en la significación y un empobrecimiento en las formas ${ }^{45}$.

\begin{tabular}{|c|c|c|c|}
\hline FORMA & ROL & OBSERVACIONES & PROCESO \\
\hline Edificio funcional & Indicio & $\begin{array}{l}\text { Percibido como } \\
\text { realidad de hecho }\end{array}$ & \\
\hline $\begin{array}{l}\text { Revestimientos, color, } \\
\text { textura, unidad... }\end{array}$ & Indicios intencionales & $\begin{array}{l}\text { Percibido como } \\
\text { realidad de hecho } \\
\text { deliberado }\end{array}$ & \\
\hline Edificio completo & Señal & $\begin{array}{l}\text { No hace falta } \\
\text { interpretar la } \\
\text { significación } \\
\text { arquitectónica }\end{array}$ & 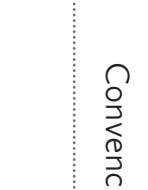 \\
\hline $\begin{array}{l}\text { Edificio histórico } \\
\text { completo }\end{array}$ & $\begin{array}{l}\text { Señal (objeto } \\
\text { restaurado) }\end{array}$ & Metafórico & $\frac{O}{\partial}$ \\
\hline $\begin{array}{l}\text { Revestimientos, color, } \\
\text { textura, unidad... }\end{array}$ & Indicio & $\begin{array}{l}\text { Percibido como } \\
\text { realidad de hecho }\end{array}$ & \\
\hline $\begin{array}{l}\text { Reconstrucciones } \\
\text { cromáticas } \\
\text { volumétricas }\end{array}$ & Indicio intencional & Sofisticación & \\
\hline Repristinaciones & Señal/Pseudoseñal & $\begin{array}{l}\text { Empobrecimiento de } \\
\text { concepto y forma }\end{array}$ & $v$ \\
\hline
\end{tabular}

Precisamente, las intervenciones sobre los bienes culturales se realizan desde la dimensión de los indicios intencionales para producir unas determinadas señales (linealidad, sensación de objeto restaurado, eliminación del lapso de tiempo entre la génesis y la actualidad, repristinaciones...). La aceptación de cierto tipo de señales puede producir una homogenización de los tratamientos de intervención. Esto ocurre cuando una señal se usa reiteradamente en el contexto de la Restauración, afectando al significado de la forma (ver TABLA 2).

\subsection{EL HORIZONTE DE EXPECTATIVAS Y LA COMPRENSIÓN DE LOS BIENES CULTURALES}

La profesora Martínez Justicia a través de las teorías del pensador ruso Mijaíl Bajtín y de las ideas de la Estética de la Recepción, introduce el concepto de horizonte

45. Idem, p. 43. 
de expectativas, para definir la limitación del intérprete de una comunicación para captar determinados mensajes. Existen cuestiones que el receptor espera, otras que no y terceras que no comprende. En este punto, se enmarca el debate actual sobre la Restauración: la interacción con los objetos histórico-artísticos y las reacciones cuando intervenimos sobre ellos.

¿Cómo rentabilizar este concepto en teoría de la restauración? En primer lugar, la noción de «horizonte» nos permite subrayar adecuadamente la historicidad radical del objeto de la restauración, señalando la variabilidad de la comprensión del mismo a lo largo del tiempo. Asimismo nos recuerda la función social del arte en su impacto sobre el horizonte de expectativas cotidiano del espectador o lector de la obra de arte y por tanto sobre su comportamiento social (...).

A la hora de acometer una intervención restauradora sobre un monumento cualquiera (sea bien mueble o inmueble) deberemos reflexionar sobre cuál es su valor en nuestro horizonte de expectativas (rastrear el proceso histórico y las valoraciones intermedias que han construido la imagen que hoy tenemos de él) y cuál puede ser el impacto que en dicho horizonte puede tener la intervención en uno u otro sentido ${ }^{46}$.

De esta forma, se reconoce la capacidad de influencia transformadora de la Restauración y, sobre todo, del restaurador. Se acepta la intersubjetividad de algunas intervenciones y se indica la necesidad de comprensión de los valores de los bienes culturales y se cuestiona la huella de los trabajos en los mismos.

En cuanto a su valor de uso o función, además de las tangibles, los objetos histórico-artísticos cumplen una función inmaterial. Ya sea como manifestación de identidad, ideología, etc., o como oferta de ocio y cultura. Por ejemplo, si una persona recibiera la tarea de reparar un telescopio, con el juego de lentes estropeado (o incluso que estas lentes provocaran aberraciones ópticas). En este caso, se sustituirían los cristales y también podría ocurrir la inclusión de lentes de última generación, aumentando las prestaciones. Si en vez de ser un telescopio cualquiera, es el que usó Galileo Galilei, esta intervención es ridícula. Igual de grotesco que intenta devolver el uso a unas termas romanas.

De esta manera, las funciones-valores simbólicos e historiográficos están determinadas por personas. Una intersubjetividad que para Muñoz Viñas, «son fruto de un acuerdo tácito entre sujetos para quienes cada objeto significa algo» ${ }^{47}$.

Por estos motivos y en este modelo de comunicación es fundamental el acto de comprensión, que Bajtín divide en varias fases: a) percepción; b) reconocimiento (comprensión del significado); c) comprensión del significado en un contexto dado y d) la comprensión dialógica. El restaurador se relaciona con la obra de arte con este esquema. La primera y segunda fase se corresponde a los estudios generales de iconografía; la tercera, corresponde al análisis iconológico; la última, requiere

46. Martínez Justicia, M. ${ }^{a}$ José, y otros: Historia y teoría de la conservación y restauración artística. Madrid, Ed. Tecnos, $3{ }^{a}$ edición, 2008, pp. 38-39.

47. MUÑoz VIÑAS, Salvador: Teoría contemporánea de la Restauración. Madrid, Editorial Síntesis, 2003, p.154. 
la comprensión histórica del concepto bajtiniano de gran tiempo; que acepta la multitemporalidad de los bienes culturales. Se sintoniza con la idea brandiana del eterno presente de la obra de arte ${ }^{48}$.

\section{CONCLUSIONES}

A pesar de que a lo largo del siglo pasado se produjo una expansión de normativas legales y textos internacionales en materia salvaguarda de bienes cultuales, no se ha remediado el menoscabo, si no la ruina, de numerosos objetos patrimoniales.

Asimismo, la propia esencia del patrimonio histórico-artístico exige la vigilancia de su autenticidad para que el recorrido de los trabajos de Restauración no pase por el lamento o la reinvención. Cuando se realizan intervenciones sobre objetos culturales se tienen que conservar sus valores originales: su imagen histórica. Sin embargo, se confirma la falta de precisión de los valores requeridos para nuestro patrimonio. De ahí la necesidad de definición de los valores y mecanismos de simbolización realizada en la primera parte del texto.

De esta forma, el uso o la reutilización puede ser la postura más poderosa para garantizar la conservación y el mantenimiento del patrimonio cultural. Pero existe una incapacidad de interpretación metodológica que lo asegure, poniendo de manifiesto las contradicciones y la complejidad del sistema. Esta incapacidad involucra a tres agentes: Públicos, profesionales y sociales.

Así, las Administraciones públicas deben ser coherentes con el cumplimiento estricto de las leyes de Patrimonio histórico. Igualmente, la responsabilidad de las Administraciones deriva, en primera instancia, de la normativa de rango legal (artículo 46 de la Constitución Española y Ley i6/1985 del PHE) y que entendemos que se debe llevar a cabo desde las siguientes políticas de actuación para posibilitar el marco de actuación sobre el Patrimonio: conservadora-vigilancia (ante atentados u olvidos con acciones de mantenimiento); curativa-sancionadora (con actuaciones sobre las causa y efectos del deterioro además de sancionar desmanes de los bienes) y educación de la ciudadanía (hacia el goce y valoración del patrimonio).

Se debe programar la financiación de las intervenciones de manera que no sea influyente en los criterios de intervención. Excluyendo todo interés que no sea público o en favor de los valores de los bienes culturales que deben quedar definidos en los estudios previos.

Será necesario el ajuste, ampliación o creación de instrumentos jurídicos y políticos de protección del patrimonio (desarrollo de formación específica en legislación patrimonial; actualizaciones, precisión y medidas concretas de la Ley de Patrimonio que atienda a cuestiones como contaminación turística, criterios específicos de intervención, definición de conceptos como «pátina», previsión legal de movimientos sociales, etc.).

48. BRANDI, Cesare: op. cit., p. 30. 
También, una mayor difusión del Catálogo de Bienes Culturales de cada localidad, que fomente la vinculación de la sociedad con su patrimonio así como la transversalidad de la educación patrimonial en las escuelas.

Por otro lado, existe un conflicto entre la exigencia que demanda la importancia y singularidad de los bienes tratados con las competencias formativas de los profesionales, con determinadas ausencias de formación teórico-práctica especializada, a nivel de educación superior. Es el caso de la proliferación de escuelas-taller o la capacitación de empresas constructoras que acceden a licitaciones de estas obras.

En la actualidad, los esfuerzos de investigación en el campo de la Restauración se dedican mayoritariamente a las cuestiones técnicas, al desarrollo de analíticas más sofisticadas, evaluaciones de nuevos tratamientos, ingeniería de productos, etc., relegando a un segundo plano la reflexión desde las ciencias sociales o la valoración crítica de la Restauración. Mientras, en la práctica, determinados trabajos se llevan a cabo de forma rutinaria y mecánica y es evidente que, en demasiados casos, los tratamientos se deciden y aplican sistemáticamente de forma estandarizada. Así, la salvaguarda del patrimonio cultural es un deber ético ineludible y la pérdida de sus valores imposibilita toda lectura crítica del pasado.

La defensa del Patrimonio debe ser una tarea social por lo que se deberá atender y facilitar las asociaciones y colectivos con este espíritu, formando una ciudadanía crítica y participativa. Además de desligar la visión reduccionista de admiración a los grandes monumentos en detrimento del valor del patrimonio popular.

Defendemos la concepción del patrimonio como un sistema comunicativo, cuyo discurso puede ser perturbado. Entonces, conviene conocer los agentes y mecanismos de alteración para comprender el despliegue del potencial expresivo de los objetos histórico-artísticos.

Esto sugiere una relativa aceptación de la «alteración» que tiene un pobre efecto físico en la durabilidad material y que imparte una apariencia visual aceptable y que lo identifica como un objeto no moderno. Este último punto es importante, porque a menudo hay confusión sobre la diferencia entre la apariencia vinculada a la intención del artista (que se trata de una condición transitoria que existe sólo brevemente) y el aspecto histórico, que reconoce al tiempo como un componente esencial de los bienes culturales y hace que se distinga las estructuras del presente. Así, cierto desgaste se considera como la respuesta inevitable de todos los materiales a su entorno, como un proceso natural.

No obstante, el ejercicio de la Restauración también porta e incorpora su propia significación. Variable a tener en cuenta en la ponderación de los valores patrimoniales. Por esta razón las intervenciones deben estar respaldadas por un conocimiento pormenorizado y análisis del objeto, además de las situaciones de riesgo que le afectan, y así, aplicar las medidas correctoras ajustadas a la problemática detectada.

Para valorar al patrimonio cultural se debe contar con un equipo interdisciplinar para dar mayor cobertura y objetividad posible. La intervención, debe basarse en el diálogo, el trabajo en equipo y el entendimiento entre la Administración, los agentes profesionales y colectivos sociales, con el conocimiento de las competencias y condiciones de cada una de las disciplinas protagonistas. 
Se plantean nuevos retos y condicionantes a la disciplina de conservación-restauración del patrimonio arquitectónico: la diversidad cultural, la amplificación de valor de la identidad y de los aspectos sociales, la aceptación de la mutabilidad de los valores culturales, la ampliación del concepto de bien cultural. La Restauración actual debe tener en cuenta estos aspectos, ir más allá de la mera capacidad técnica para resolver una falta de figuración y desechar la seducción por la corrección/ perfección entendida como búsqueda de la repristinación.

Como Brandi advirtió, toda restauración es un producto de su tiempo y, como tal, es un acto de interpretación crítico. Restauramos con una intención y ésta debe ser cuestionada continuamente al igual que la obra misma. 


\section{Dossier Cómplices Necesarios por Carlos Reyero Hermosilla - Dossier Necessary Accomplices by Carlos Reyero}

2) CARLOS REYERO

Introduction: Necessary Accomplices / Presentación: Cómplices necesarios

25 Encarna Montero Tortajada

The Oligarch and the Brushes: a Biographical Sketch of Andreu Garcia, priest / El oligarca y los pinceles: breve semblanza del presbítero Andreu Garcia

María Alegra García García

Some aspects about archbishop of Toledo don Juan Martínez Silíceo's iconography (c.1477-1557) / Algunos aspectos en torno a la iconografía del arzobispo de Toledo don Juan Martínez Silíceo (c.1477-1557)

\section{FELIPE PEREDA}

Performing Doubt: the Art of Believing in Early Modern Spain / El ejercicio de la duda: el arte de creer en la España alto Moderna

\section{Jesús-PEdRo LoREnTE LORENTE}

The mouseion ideal reinterpreted as art colony on the outskirts of Darmstadt and Hagen / El ideal del mouseion reinterpretado como colonia artística en las afueras de Darmstadt y Hagen

\section{9}

NÚRIA FERNÁNDEZ RIUS \& NURIA PEIST

The photographic and the mediation system. Artistic, technical and commercial values in the beginning of photography / Lo fotográfico y el sistema mediador. Valores artísticos, técnicos y comerciales en los inicios de la fotografía

\section{Elena Marcén Guillén}

Real museum, imaginary museum. Considerations around the concept of museum as metamorphosis scenery / Museo real, museo imaginario. Reflexiones en torno al concepto de museo como escenario de metamorfosis

147 VICENÇ FURIÓ

Fame and prestige: necessary and decisive accomplices in the case of Hilma af Klint / Fama y prestigio: cómplices necesarios y decisivos en el caso de Hilma af Klint

\section{Miscelánea $\cdot$ Miscellany}

De la aljama a la primitiva construcción gótica. Reflexiones a propósito de la Catedral de Jaén en época bajomedieval / From the Great Mosque to the former Gothic construction. Some observations on Jaén's Cathedral during the late middle ages
199

TERESA IZQUIERDO ARANDA

Carpintero y maestro constructor en la arquitectura gótica valenciana / Carpenters and building mason in the Gothic architecture in Valencia $\left(14^{\text {th }}-15^{\text {th }}\right.$ centuries)

223

ANTONIO JosÉ DíAZ FERNÁNDEZ

El arquitecto madrileño Pedro de la Torre en Toledo y un retablo inédito localizado / The Architect of Madrid Pedro de la Torre in Toledo and a located unpublished altarpiece

24.7 Fernando R. Bartolomé García \& Laura Calvo García

Transformaciones en el retablo mayor de San Miguel Arcángel de Lazkao (Gipuzkoa). Del Barroco al Neoclasicismo / Changes in the main altarpiece of Saint Michael the Archangel in Lazkao (Gipuzkoa). From Baroque to Neoclassicism

\section{Francisco JaVIER LÁZARO SEBAStiÁN}

La renovación de la fotografía española a partir de la pauta estética del realismo. Un precedente formal y significativo en el reportaje de Eugene Smith sobre Deleitosa (Cáceres) / The renovation of the Spanish photography from the aesthetic guideline of the realism. A formal and significant precedent in Eugene's Smith photographic article on Deleitosa (Cáceres)

277 Javier Cuevas del Barrio

El posicionamiento de Sigmund Freud ante el Surrealismo a través de la correspondencia con André Breton / The position of Sigmund Freud regarding Surrealism through correspondence with André Breton

295 Alicia SÁnCHEZ ORTIZ

El vacío iluminado del negro / The illuminated void of black

317 Óscar MuÑoz Sánchez

Santiago Serrano (1970-1980): Hacia una pintura no aprehensible / Santiago Serrano (1970-1980). Towards a non-apprehensible painting

347 Antonio Jesús Sánchez FERnÁndeZ

Restauración y metamorfosis de los valores del patrimonio cultural / Restoration and Metamorphosis of the Values of Cultural Heritage

\section{Reseñas · Book Review}

375

Aricò, Nicola. Architettura del Tardo Rinascimento in Sicilia. Giovannangelo Montorsoli a Messina (1547-57). Firenze, Leo S. Olschi Editore, 2013. (AlICIA CÁmARA MuÑoz)

Combalía, Victoria. Dora Maar. Barcelona, Circe, 2013. (AMPARO SERRANO DE HARO)

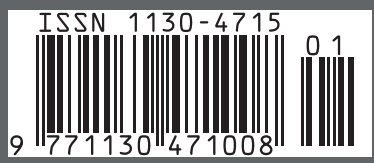

